\title{
Analisis Daerah Rawan Bencana Tanah Longsor Berdasarkan Zona Water Content Di Desa Olak Alen Kecamatan Selorejo, Blitar
}

\author{
Maulidah Aisyah, Widya Utama, dan Wien Lestari \\ Departemen Teknik Geofisika, Fakultas Teknik Sipil Dan Perencanaan, Institut Teknologi Sepuluh \\ Nopember (ITS) \\ e-mail: wu.explorer@gmail.com
}

\begin{abstract}
Abstrak-Salah satu penyebab terjadinya tanah longsor yaitu adanya zona jenuh air atau zona tersaturasi air dimana terdapat kondisi terakumulasinya air pada suatu lapisan tanah yang sukar meloloskan air. Kondisi tersebut dapat diketahui dengan metode geolistrik resistivitas dengan konfigurasi Wenner-Schlumberger karena dapat menerjemahkan kondisi bawah permukaan secara horizontal maupun lateral dengan baik berdasarkan nilai resistivitas. Nilai zona jenuh air yang terlihat yaitu antara 4,39 $9,29 \Omega \mathrm{m}$. Berdasarkan peta rawan bencana yang telah dibuat, faktor penyebab terjadinya tanah longsor adalah curah hujan, tutupan lahan, dan kelerengan. Hasil pemetaan yang telah dilakukan menunjukkan bahwa Kecamatan Selorejo merupakan salah satu daerah yang kerawanan longsornya bernilai sedang, yakni diantara 24,03.
\end{abstract}

Kata Kunci-Tanah longsor, Zona Jenuh Air, Geolistrik.

\section{PENDAHULUAN}

G ERAKAN tanah merupakan salah satu proses geologi yang terjadi akibat interkasi beberapa kondisi antara lain geomorfologi, struktur geologi, hidrogeologi dan tata guna lahan. Kondisi yang saling berpengaruh tersebut dapat mewujudkan kondisi lereng yang cenderung bergerak [1] Pergerakan tanah dapat diketahui dengan tanda-tanda seperti munculnya retak tarik dan kerutan di permukaan lereng, miringnya pepohonan, hilangnya kelurusan fondasi bangunan dan lainnya [2].

Kabupaten Blitar merupakan salah satu kawasan di Jawa Timur dengan kondisi geologi berupa pegunungan vulkanik pada bagian utara dan bagian selatan merupakan dataran rendah. Dengan adanya kawasan pegunungan pada bagian utara inilah membuat Kabupaten Blitar termasuk dalam zona rentan pergerakan tanah. Salah satu Kecamatan yang rawan tanah longsor merupakan Kecamatan Selorejo dengan tingkat gerakan tanah menengah.

Salah satu cara untuk mengetahui daerah yang rawan longsor adalah dengan membuat peta rawan bencana longsor. Dari peta tersebut, kita dapat mengetahui daerah mana saja yang perlu dilakukan pencegahan bencana longsor. Tujuan dari penelitian ini adalah menentukan zona jenuh air dengan metode resistivitas dan memetakan daerah rawan bencana tanah longsor dengan batasan daerah hanya di Desa Olak Alen Kecamatan Selorejo, Kabupaten Blitar dan menggunakan metode resistivitas konvigurasi Wenner-Schlumberger sebanyak 4 line.

\section{METODE PENELITIAN}

\section{A. Lokasi Penelitian}

Lokasi pengukuran di Desa Olak Alen, Kecamatan Selorejo, Blitar berjumlah empat lintasan menggunakan resistivitas konfigurasi Wenner-Schlumberger.

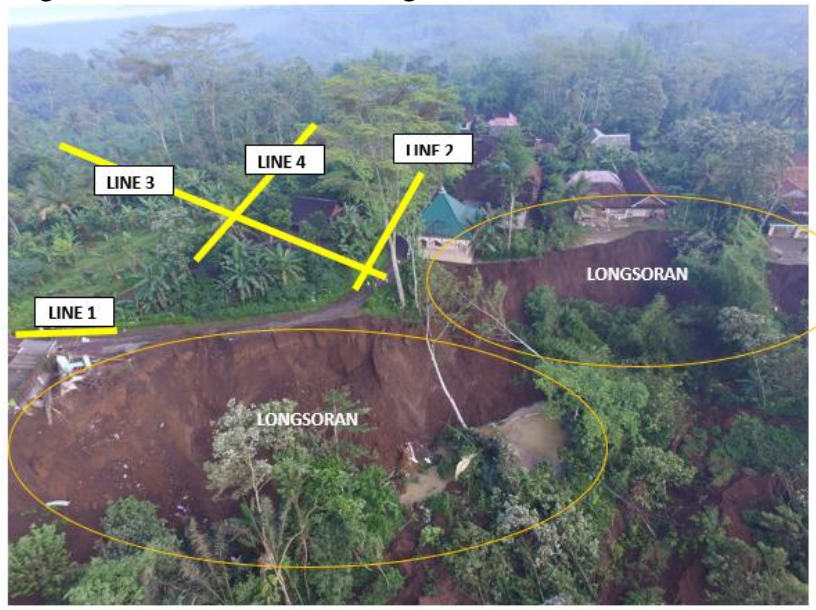

Gambar 1. Lokasi pengukuran dilakukan 4 line pada daerah sekitar longsor.

\section{B. Pengolahan Data}

Setelah dilakukan proses pengumpulan data, kemudian diolah berdasarkan diagram alir sebagai berikut. 


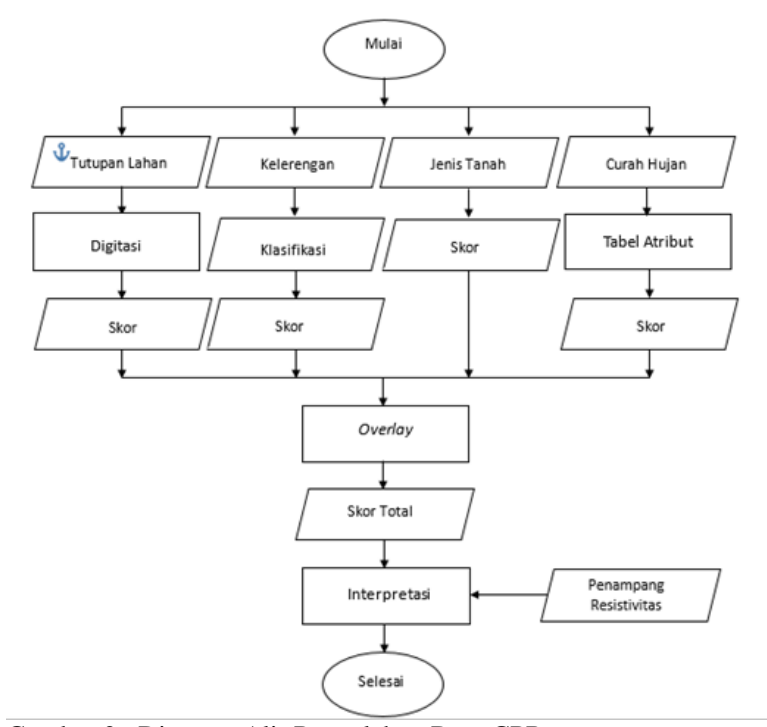

Gambar 2. Diagram Alir Pengolahan Data GPR.

\section{HASIL DAN DISKUSI}

\section{A. Analisis Data Geolistrik}

Dari hasil pengolahan data resistivitas yang sudah di inversi, dapat dikategorikan beberapa indeks warna, yaitu:

Tabel 1.

Material bawah tanah line 1-line 4

\begin{tabular}{|c|c|c|}
\hline Nilai Resistivitas ( $\mathbf{\Omega m})$ & Warna & Material \\
\hline $4.39-9.39$ & 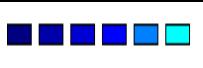 & $\begin{array}{c}\text { Lanau pasiran } \\
\text { (tersaturasi air) }\end{array}$ \\
\hline $11.9-16.9$ & $\square \square \square \square \square \square$ & Lanau pasiran \\
\hline $19.4-32.9$ & $\square \square \square \square \square$ & Lanau Pasiran \\
\hline
\end{tabular}

Indeks warna yang cenderung biru memiliki nilai resist antara $4.39-9.39 \Omega \mathrm{m}$. Arti fisis dari nilai dan warna yang menunjukkan pada gambar tersebut yaitu daerah tersebut merupakan daerah yang diisi oleh material lanau pasiran yang terdapat zona jenuh air atau zona tersaturasi air didalamnya. Hal tersebut didukung dengan tanda di lapangan berupa crack atau rekahan kecil yang ada di permukaan. Air akan masuk melalui crack kecil tersebut dan mengisi material dibawahnya, kemudian air tersebut terjebak karena material dibawahnya merupakan material yang memiliki permeabilitas kecil.

Sedangkan untuk nilai resistivitas yang tinggi ditandai dengan warna merah sampai ungu. Pada penampang terlihat warna merah dan ungu berada di bagian titik akhir pengukuran line 2 dan line 3 . Jenis material yang mengisi cenderung sama, namun jika dilihat dari nilai resistivitasnya, maka sangat memungkinkan adanya rongga-rongga lebih besar yang terisi oleh udara. Pada line 2 dan line 3 yang berpotongan terlihat warna yang dominan yaitu merah dan ungu. Dan apabila dikorelasikan dengan keadaan sebenarnya di lapangan, daerah tersebut merupakan daerah yang banyak terdapat rongga besar yang berisi udara yang dapat mempengaruhi gerakan tanah yang dapat menyebabkan tanah longsor.

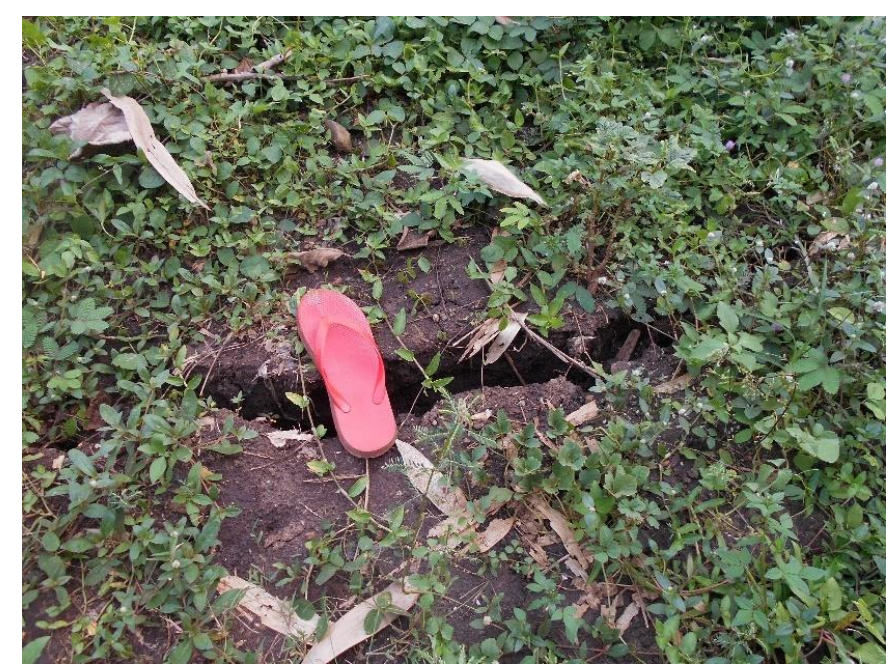

Gambar 3. Salah satu retakan besar diantara line 2 dan line 3.

\section{B. Analisis Peta Rawan Bencana Tanah Longsor}

Data hasil pengolahan resistivitas menunjukkan bahwa pada daerah penelitian terdapat zona jenuh air dengan nilai resistivitas $4.39-9.39 \Omega \mathrm{m}$. Dari hasil pengolahan tersebut dapat diketahui jenis material yang ada dibawah permukaan sampai kedalaman 16 meter. Pada daerah pengukuran, jenis materialnya yaitu pasir kelanauan. Perbedaannya dapat dilihat dari nilai resistivitasnya, apabila nilai resistivitasnya semakin kecil maka dapat diasumsikan bahwa daerah tersebut memiliki material pasir

Data resistivitas diatas mendukung peta rawan bencana yang telah dibuat. Pada peta rawan bencana tanah longsor Kabupaten Blitar, daerah penelitian memiliki nilai kerawanan 24,04 yang berarti cukup rawan.

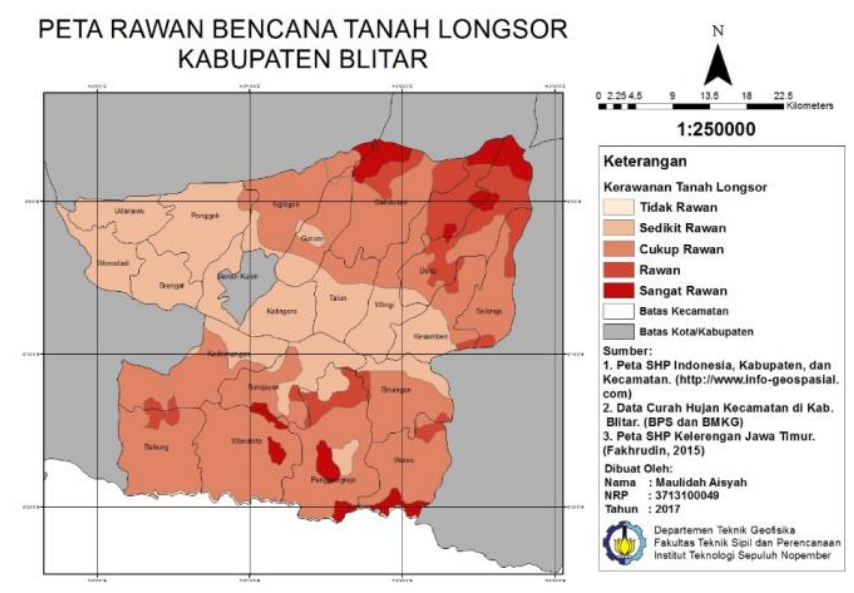

Gambar 4. Hasil Peta Rawan Bencana Tanah Longsor Kabupaten Blitar.

\section{KESIMPULAN DAN SARAN}

A. Kesimpulan

Kesimpulan yang didapat dari penelitian ini adalah:

1) Nilai resistivitas $4,39-9,39 \Omega \mathrm{m}$ terdapat pada kedalaman 10-20 meter pada lintasan 1, 6-18 meter pada lintasan 2, 820 meter pada lintasan 3, dan 10-18 meter pada lintasan 4 .

2) Zona jenuh air terdapat pada kedalaman 10-20meter dengan nilai resistivitas 4,39-9,39 $\Omega \mathrm{m}$. 
3) Berdasarkan peta rawan bencana tanah longsor, Kecamatan Selorejo merupakan daerah dengan tingkat kerawanan 24,04 yang berarti cukup rawan.

\section{B. Saran}

Saran yang dapat diberikan berdasarkan hasil dan kesimpulan untuk membangun hipotesa-hipotesa selanjutnya adalah:

1) Di Kabupaten Blitar terdapat beberapa kecamatan yang terindikasi rawan bencana tanah longsor, sehingga perlu dilakukan akuisisi data geolistrik resistivitas pada daerah rawan tersebut agar dapat dikorelasikan dengan peta rawan bencana tanah longsor.

2) Dari data tutupan lahan Kabupaten Blitar, jumlah penanaman vegetasi untuk membantu mencegah bencana tanah longsor masih kurang. Pemanfaatan lahan-lahan yang memiliki kelerengan cukup tinggi masih berupa kebun yang bercampur dengan pemukiman dan sawah. Sebaiknya dimulai menanam tanaman yang berakar tunggang seperti sengon atau tanaman sejenis untuk menopang tanah yang berada di lereng yang curam.

3) Dilakukan monitoring disetiap daerah yang sudah terindikasi bencana tanah longsor dengan cara pemasangan sensor pergerakan tanah agar setiap gerakan tanah dapat terindikasi lebih dini dan ditangani dengan tepat.

\section{DAFTAR PUSTAKA}

[1] D. Karnawati, "Bencana Alam Gerak Massa Tanah di Indonesia dan Upaya Penanggulangannya," Universitas Gajah Mada, 2005.

[2] H. . Hardiyatmo, Penanganan Tanah Longsor dan Erosi. Yogyakarta: Gadjah Mada University Press, 2012. 